ARTICLE

\title{
A club's contribution to global climate governance: the case of the Climate and Clean Air Coalition
}

\author{
Charlotte Unger (1D ${ }^{1 凶}$, Kathleen A. Mar ${ }^{1} \&$ Konrad Gürtler ${ }^{1}$
}

\begin{abstract}
Not only is the climate changing, but so is global climate governance. Climate policy initiatives have proliferated within and beyond the United Nations Framework Convention on Climate Change (UNFCCC) regime in a polycentric pattern. Nevertheless, promised action under the Paris Agreement (PA) is far from being sufficient to achieve its targets of keeping global warming below $2{ }^{\circ} \mathrm{C}$. A special research focus has emerged on international 'climate clubs', referring to a smaller group's greater ability to make progress in international climate policy compared to large global forums. Against this background, our paper reflects on the club functions of the Climate and Clean Air Coalition (CCAC), a transnational partnership that aims at slowing the rate of near-term global warming through the reduction of short-lived climate pollutants (SLCPS). How does the CCAC contribute to global climate governance and how does this relate to existing structures, such as the UNFCCC process and the PA? Researchers have generally found that climate clubs can raise ambition, produce emissions reductions, and/or enhance cooperation, while generating additional benefits for its members. However, their specific governance contribution remains rather opaque, for example, how emissions reductions are achieved. There is a lack of analytical application, knowledge of the political practice and of in-depth case studies of the clubs concept. This paper contributes to filling this gap by applying central aspects of clubs research, namely membership and size, public goods, and the provision of additional benefits as an analytical framework in one in-depth case study of a governance initiative that has not yet been the subject of academic scrutiny: the CCAC. The results are based on expert interviews and the analysis of strategic and academic documents. Overall, this research finds that the CCAC's largest contribution to global climate governance lies in preparing SLCP emissions reductions through raising awareness, orchestrating different actors and actions related to SLCPs, and establishing a large technical cooperation network. To some degree it also directly implements SLCP reduction projects. Ultimately, it complements the UNFCCC and especially the Paris Agreement. Members are part of the CCAC because its benefits go beyond climate change mitigation. Its large transnational membership constellation both supports and challenges its governance contribution.
\end{abstract}

\footnotetext{
${ }^{1}$ Institute for Advanced Sustainability Studies, Potsdam, Germany. ${ }^{凶}$ email: charlotte.unger@iass-potsdam.de
} 


\section{Introduction}

he first two decades of the 21st century have seen an immense number of new policies, regulations, and initiatives representing manifold responses to the challenge of climate change. As of 2017 , about $70 \%$ of worldwide greenhouse gas emissions (GHG) have been covered by national climate strategies or regulations (Iacobuta et al., 2018). Under the Paris Agreement (PA) of the United Nations Framework Convention (UNFCCC) countries have pledged to pursue efforts to keep global warming at 'well below $2{ }^{\circ} \mathrm{C}$ ' through their Nationally Determined Contributions (NDCs). The sobering evidence is, however, that these commitments are far from sufficient if added up; we need to roughly increase our promised emissions reductions fivefold to achieve the $1.5^{\circ} \mathrm{C}$ target (UNEP, 2018).

This situation underscores the need for urgent action beyond and in addition to what has been promised under the PA so far. Seen from an analytical perspective, it also gives impetus for the dynamics of the evolving climate policy landscape, namely the evolution of a complex, polycentric international climate governance architecture. Global climate governance takes place in multifaceted forms ranging from international environmental agreements to activities without strict legal character, such as climate strategies, action plans, non-binding programs, and mechanisms. The observation that global governance is increasingly shared by non-state actors (Jang et al., 2016) also holds true for climate policy: beyond the traditional category of states, subnational and regional actors, transnational coalitions, partnerships and alliances are active at the global governance level.

How do such innovative actors contribute to global climate governance and how does this relate to existing structures, such as UNFCCC process and the PA?

A growing body of literature takes stock of and examines such climate governance initiatives. Within this context, one approach looks at climate clubs, referring to alliances of actors with limited state and/or non-state membership. Before the adoption of the PA, many researchers assumed that these climate clubs would strengthen countries' commitments and pave the way for an international climate agreement (Hale, 2011; Victor et al., 2007; Widerberg and Stenson, 2013). More recently, scholars argue that their role lies broadly in contributing to emissions reductions or making more progress in international climate policy cooperation (Stewart et al., 2017; Hovi et al., 2016; Potoski, 2017). Further research that looks at mini-lateral and non-state climate initiatives describes their contribution as preparing the implementation of existing governance structures, and orchestrating the activities of several actors and actions (Abbott et al., 2015; Chan et al., 2018; Hermwille, 2018).

Notwithstanding, there is a lack of research exploring the specific nature of climate clubs' climate governance contributions. For this purpose a better knowledge of the political practice would be necessary. Existing literature provides an overview and categorization of existing climate clubs (i.e. Weischer et al., 2012), but stops short of in-depth analyses and case studies of climate governance actors in general and of transnational climate clubs specifically.

This paper takes up the climate clubs concept in order to examine the case of the Climate and Clean Air Coalition (CCAC). The CCAC is a voluntary, transnational partnership that aims at reducing near-term climate change impact through the integration of pollutants that affect air quality and the climate. Our paper aims to make a contribution in several inductive ways: by structuring existing conceptual assumptions of climate clubs, extracting empirical insights, and deepening the understanding of a specific case: the CCAC as a representative of an innovative global climate governance actor. To the best of our knowledge no academic analysis of the CCAC has been published. We ultimately draw conclusions on the CCAC's contributions to climate policy and examine it as a concrete example of how innovative global climate governance actors can support global processes such as the UNFCCC. We conclude that the CCAC has the prerequisites to make a relevant contribution because of its numerous and diverse members, who participate in this club not only because of the common objective of near-term climate change mitigation, but also because they receive benefits beyond this overall goal, e.g. technological support. We see the general contribution of the CCAC coming closer to research that sees a 'softer' role for clubs: not in achieving immediate emissions reductions or more ambitious reduction commitments, but rather in preparing and supporting policies, orchestrating actors and creating awareness. We argue that these activities have an added value for international climate governance, because the topic of SLCPs is politically underrated, not tackled under the UNFCCC process, and is characterized by a still-incomplete scientific knowledge basis.

This article starts off with a glimpse into the academic discussion on the international climate governance architecture and then focuses on climate clubs. Three criteria for climate clubs are distilled from existing approaches and then used as an analytical framework for understanding the nature of the policy contribution made by the CCAC. These three criteria are (1) club membership and size; (2) public goods; and (3) additional benefits or 'club goods'.

In addition to analyzing strategic and academic documents, we base our research on semi-structured expert interviews. Interviews were conducted with political and academic experts working with, for, or on the CCAC, including countries, Intergovernmental and Non-governmental Organizations (IGOs and NGOs). As our focus is on inside-perspectives from the CCAC, a majority of interviews were realized with participants from CCAC member organizations. ${ }^{1}$

\section{Global climate governance architecture today: innovative governance initiatives and climate clubs}

The empirical reality in the last decade has fueled academic debates: Slow progress and the failure to include major emitters in agreements like the Kyoto Protocol were symptomatic in the 2000s and led to perceived gridlock in the formal channels of climate policy-making. The fatal Copenhagen UNFCCC summit in 2009 (Conference of the Parties (COP) 15) ended without an agreement. Failure in the international negotiations left many constituents frustrated with the multilateral process (Hovi et al., 2016; Eckersley, 2012). Since then, the climate policy landscape has broadened significantly and become very complex (Pattberg and Widerberg, 2017): governance innovations have emerged on all governmental levels, and diverse non-governmental actors play a role ranging from traditional environmental movements to the private sector and to mixed policy initiatives.

These developments have spurred research interest around the emergence and structure of the global (climate) governance architecture and its trend towards polycentricity (Jordan et al., 2015; Oberthür, 2016; Ostrom, 2010) and fragmentation (Biermann et al., 2009; Pattberg et al., 2014; Zelli, 2011). The international climate policy landscape has become polycentric, referring to a situation where multiple governing bodies with considerable independence operate at different scales, complementing the centralized global decision-making (Ostrom, 2010). It is also fragmented, as international institutions co-exist with different characters, constituencies, spatial scope, and subjects within one policy domain (Biermann et al., 2009).

Against this background, a research focus has evolved around exploring the role of innovative transnational and non-state 
governance initiatives that complement the UNFCCC policy process; for example, their potential to contribute to closing the gap between national commitments and overall targets of the PA (Chan et al., 2018; Graichen et al., 2016; Hermwille, 2018; Michaelowa and Michaelowa, 2017). A central term applied by many of these studies is that of orchestration, referring to a situation where international and transnational actors (including UNFCCC) coordinate, initiate, direct, or manage in a rather soft manner (Abbott et al., 2015; Chan et al., 2018; Hermwille, 2018). Other authors have highlighted that transnational partnerships can serve a bridging function, overcoming fragmentation through permitting dialogue in spite of persistent political conflicts (see Gupta et al., 2016 on the REDD+ Partnership).

In the realm of the above-mentioned political developments after COP15 and the described academic debate, the concept of climate clubs as one of these innovative, sometimes transnational governance actors, gained momentum. 'Clubs' thinking is rooted in economics and started with the assumption that smaller groups of actors can make more progress through being more ambitious in creating optimal outcomes, such as goods and cooperation (Buchanan, 1965; Olson, 1971), since negotiation becomes easier (Eckersley, 2012). The concept was then applied to trade, environment, and climate-related issue areas (see e.g. Abbott, 2012; Prakash and Potoski, 2006).

'Climate clubs' have received increasing attention after countries were unable to reach an international agreement in 2009 (Falkner et al., 2010; Hale, 2011; Hovi et al., 2016, 2017; Keohane and Victor, 2011, 2016; Nordhaus, 2015; Sabel and Victor, 2015; Victor, 2015, 2017; Weischer et al., 2012; Widerberg and Stenson, 2013). A controversial debate was led on the question whether climate clubs complement or conflict with the UNFCCC (Widerberg and Stenson, 2013), for example through bypassing or distracting action on the main $\mathrm{GHG} \mathrm{CO}_{2}$. However, most authors agree that climate clubs have a rather contributing role for the UNFCCC process (Widerberg and Stenson, 2013; Victor, 2015). Some authors have sought to categorize and locate existing clubs in the international climate policy landscape (Weischer et al., 2012), while other approaches have concentrated on the conditions and constellations on under which a club can be effective (Hovi et al., 2017).

In the academic debate, no agreement on a definition of climate clubs, or on what their specific function is or should be, exists. Nordhaus (2015, p. 1340) proposes that a club is "a voluntary group deriving mutual benefits from sharing the costs of producing an activity that has public-good characteristics." Alternatively, Hovi et al. (2017, p. 2) outline "a climate club as any international actor (country) group that (1) starts with fewer members than the UNFCCC has and (2) aims to cooperate on climate change mitigation." Prakash and Potoski (2007) suggest distinguishing between Buchanan (economic) clubs that have the purpose of club good production, and voluntary clubs that aim to produce beneficial social externalities. As climate action is first and foremost dedicated to public rather than private good creation (Falkner, 2016), climate policy initiatives hardly exist in the sense of economic clubs. Building on that, Green (2015) introduced pseudo-clubs as a third category, which refers to initiatives with non-binding standards, without compliance control. Recently, Stewart et al. (2017) proposed to understand the concept as a continuum of club-like arrangements, which includes the whole range from classic economic clubs to looser forms of coalitions.

Summarizing, we can say that a commonality of many conceptualizations is that they understand climate clubs as a governance option that makes progress in international climate policy that is different than the centralized UNFCCC process. Some authors suggest what this progress could be: literature published before the PA's adoption highlights clubs as a more effective diplomatic approach to frame out deals (Hale, 2011; Victor, 2015; Widerberg and Stenson, 2013) or an option to assist in catalyzing emissions reduction targets in line with science (Weischer et al., 2012). After the adoption of the PA researchers examined how a club or smaller group of actors can foster effective cooperation (Hovi et al., 2017; Sælen, 2016). Even though several authors argue that climate clubs can spur emissions reductions (Stewart et al., 2017; Hovi et al., 2016; Potoski, 2017), many studies stay opaque on how this is done. Stewart et al. (2017) suggest clubs can incentivize additional emissions reductions to those promised under the UNFCCC through shifting the incentive structure towards non-climate benefits, for example reduced energy costs. They see clubs as part of a building blocks strategy: blocks consisting of new, voluntary transnational mechanisms targeting multiple sectors, themes, or measures related to climate change build up to a strategy that broadens the efforts committed under the UNFCCC. This helps to implement and increase the effectiveness of the PA and may support the increase of ambition in future updates of commitments under the PA (Stewart et al., 2017).

\section{Methodological approach}

This paper uses existing clubs conceptualizations and knowledge from transnational governance studies and develops an analytical framework for understanding how, why and what progress a climate club makes in international climate policy. We then use this framework to examine one specific club, the CCAC. Our qualitative research approach takes into account data from reports and other material published by the CCAC and interviews realized mainly with CCAC members. Fourteen expert interviews were carried out with CCAC partners, including country members from Latin America, Europe, Central Asia, Africa; research institutions, NGOs, intergovernmental institutions and the CCAC Secretariat in the time between April and October 2018. Interviewees were selected to reflect CCAC structure and membership, including new members, CCAC founding members, and those with several years of CCAC experience. Interviews were realized through a semi-guided approach, based on a common questionnaire with open questions. This proceeding gave the interviewee room for detailed descriptions, personal opinions and the possibility to bring up facts not asked through the questionnaire. Additional information on the interviews can be found in the "Data availability" section.

In the following sections, we establish three climate club criteria based on common understandings from existing research on clubs and transnational actors. Evaluation of (1) club membership and size provides knowledge on the relevance of a club, its political weight and its future prospects; examination of (2) public goods provides insight into how a club can make a governance contribution; and consideration of (3) additional benefits or 'club goods' helps to understand the motivations for members to participate in the club. The criteria are closely interlinked and to some degree overlapping. Such an approach has not been applied in the climate clubs literature, although similar categories are of common use in the climate change regime research (i.e. see Barret, 2008). We see our qualitative research as complementary to approaches such as Agent-Based Models (ABM) and climate economics-based models, which have been applied to understand how climate clubs emerge and can be effective (Hovi et al., 2016, 2017; Nordhaus, 2015). These modeling studies explore the conditions and actor constellations under which cooperation in club form could lead to emissions reductions, for example via conditional commitments and side payments. As many authors have observed, however, there are no "credible" climate clubs in 
existence, when their record is judged on the metric of achieved or committed emissions reductions (Hovi et al., 2016, 2017). Our qualitative analysis places the focus on exploration of the political practice, where we can consider clubs contributions that are difficult to quantify, e.g., generation of support for policies. It can thus explore the question of what type of contribution (if any) is made. This is especially pertinent for the CCAC, where the data is insufficient to make a robust, quantitative accounting of emissions reductions. Further, since interviews were carried out primarily with CCAC members and the available reports were published by the CCAC, the data at hand do not allow for an objective evaluation of the CCAC's effectiveness, and rather lend themselves to a qualitative approach.

\section{Climate clubs criteria}

Club membership and size. A climate club must have relevant membership and adequate size to be able to make a contribution to international climate governance. In order to be effective, a club should include a 'critical mass' of actors relevant for solving the specific problem, i.e., climate change (Falkner, 2016; Hovi et al., 2017; Victor, 2015). Such relevance can be defined in terms of GHG emissions (e.g. Hovi et al., 2017; Naím, 2009), targeting the most responsible, vulnerable or capable countries, or along the dimensions of power (Falkner, 2016), legitimacy, and willingness (Hale, 2011). Integrating intergovernmental organizations and non-state members, such as scientific institutions, NGOs and the private sector can be beneficial, because they can bring knowledge, expertise and action where intergovernmental governance is insufficient (Bulkeley et al., 2014; Hale, 2011). In climate clubs, members are united based on the common goal of combatting climate change.

In general, club size is a decisive criterion for the club's existence over time and for its success and effectiveness. Researchers discuss different optimal club sizes ranging from small one-digit numbers for emerging clubs (Hovi et al., 2017; Naím, 2009) to 20 members (Naím, 2009). A climate club can also start small and grow over time (Weischer et al., 2012). The upper limit of club membership is less discussed in research. However, Green (2015) argues that so-called 'pseudo-clubs' have typically a fluid membership due to a lack of entry barriers or enforcement rules.

In our analysis, we use examination of club membership and size to evaluate whether a climate club can make a relevant contribution. This research takes the following aspects as indicators for relevant membership and size of the CCAC: (a) capability and problem-solving capacity: members should cover a major share of the world's emissions, be responsible for SLCPaffected areas, and/or have strong economic capacity; (b) legitimacy: a club can be considered legitimate if it includes both the responsible and affected actors; climate clubs should include both members with historical responsibility and those who are especially vulnerable to the problem of climate change and in this case SLCPs pollution. Transnationality, through the inclusion of non-state actors, can both increase the problem-solving capacity and contribute to legitimacy; (c) a common objective: members join the club in order to tackle a common objective or specific aspect of climate change mitigation.

Public goods. A climate club must generate public goods and perform governance in order to contribute to international climate governance (Green, 2015; Prakash and Potoski, 2007). We understand successful governance activities contributing to climate change mitigation as the central public good that climate clubs can produce. Such governance activities can take at least four general forms. Firstly, clubs can actively engage in emissions reductions by carrying out climate protection projects and onthe-ground GHG reduction activities. Secondly, they can incentivize policies and provide institutional mechanisms and programs, supplementary to efforts in the UNFCCC (Potoski, 2017). We categorize such policy support as public good in this context because of its central role within governance, and because principally, nobody can be excluded from the resulting climate benefits. $^{2}$

Thirdly, they can foster political dialogue, for instance, on a neglected topic through raising awareness (Weischer et al., 2012). Fourthly, climate clubs can provide a forum to enhance cooperation and technical exchange. Clubs enhance cooperation through their informal discussion atmosphere and low pressure to achieve formal deals (Falkner, 2016). In addition, they may create a 'playing field' where informal testing of cooperation and technical experimentation can lead to deeper cooperation (Hovi et al., 2017). This function has also been called a 'building block approach' to a larger climate regime (Potoski, 2017; Stewart et al., 2013). While activities such as dialogue, exchange, and cooperation are sometimes limited to club members, we consider these activities to be core climate governance activities. In our analysis, we examine what activities the club undertakes to create public goods in order to understand the club's contribution to international climate governance, and ultimately to mitigating climate change. In this analysis we use the following indicators: (a) active emissions reductions: a climate club creates a public good if emissions reductions on the ground can be attributed to its activity; (b) support of policy planning: a climate club contributes to climate governance if it plays a role in the development of policy that advances climate mitigation; (c) advancing political dialogues: a climate club creates the contributes to global climate governance if it engages in strategically oriented activities that raise awareness and increase support for the topic; (d) cooperation enhancement; a climate club creates a public good by facilitating regular exchange and coordinated work on a specific topic.

Additional benefits or 'club goods'. A climate club should generate benefits for it members that go beyond the common goal of climate governance, to provide incentives for their participation. From an economic perspective, this creation of benefits is central (Buchanan, 1965; Prakash and Potoski, 2007). Several authors argue that a club must provide incentives for potential members to join and to stay onboard (Hale, 2011; Hovi et al., 2017), These 'club goods' should be private in the sense that only members can consume them and non-club members can be excluded from these benefits (Green, 2015).

Even though we agree that a climate club should generate gains beyond global climate change mitigation in order to incentivize members to join and be active, we question the condition on the strict exclusive nature of these benefits. As climate change mitigation is per se non-exclusive, all related activities will have some public benefit. A club must rather generate 'additional' benefits: benefits that would not have been created in the absence of the club, which do not have to be entirely exclusive, but benefit the clubs members first and foremost (Steward et al., 2017; Hannam et al., 2017).

For example, the dissemination of technologies and mitigation strategies, e.g. on energy efficiency (Potoski, 2017; Stewart et al., 2013) could be counted as a club benefit. Sælen (2016) discusses side-payments or (financial) transfers to make potential candidates join the club. Also non-material goods, such as the building of trust and reputation that comes with the name of the club (Green, 2015), can be seen as additional goods. Regular and informal meetings within a club can create a strong connection between members and eventually lead to deeper trust between 
partners over the years. Being a club member can create reputational benefits, such as prestige (Stewart et al., 2017) and demonstrate a superior environmental activity and performance (Potoski, 2017). The club name can function as a label for an internationally recognized practice or methodology and therewith legitimizes policies. The recognition of this certification by other stakeholders, such as societal groups or governmental regulators can be important (Potoski, 2017). The club could also provide non-climate benefits (Stewart et al., 2017): such co-benefits, for example reductions in energy costs, could occur in the form of positive side effects of the mitigation activities.

In our analysis we examine whether a climate governance initiative provides additional benefits to its members and whether they see these as reason for joining or staying in the club. We consider the following categories of additional benefits: (a) financial incentives: members gain financial advantages; (b) knowledge incentives and methodologies: members have access to the club's knowledge products or expertise; (c) reputational benefits: being a member brings some kind of prestige or the prestigious name facilitates other governance activities; (d) trustbuilding: participation in the club has increased trust within club members; (e) co-benefits: members receive additional benefits that are produced as positive side effects from the clubs' mitigation activities, e.g., for sustainable development.

Figure 1 provides an overview of the applied clubs criteria.

\section{The CCAC's climate club functions}

In February 2012, the CCAC was established as a multilateral voluntary partnership "for concrete and substantial action to accelerate efforts to reduce short-lived climate pollutants (SLCPs)" (CCAC, 2014a). The partnership includes national and subnational governments, intergovernmental organizations, businesses, scientific institutions and civil society organizations. Founded by six governments and the UN Environment Programme (UNEP), the CCAC consists of 69 state and 76 non-state partners at the date of writing. The CCAC secretariat is hosted by UN Environment and based in Paris. Further, an elected steering committee has the role of oversight body and the final say in most decisions, for example the destiny of funding. Funding is donated by members on a voluntary basis into a trust fund that is spent on the CCAC Secretariat, as well as on-the-ground SLCP reduction projects and other strategic activities, including research, conferences, and working-level as well as high-level political meetings (CCAC, 2014a). Amounting to a total of US\$ 80 million by 2017 (CCAC, 2017a), its financing is rather small for such a large organization. While funding comes solely from developed

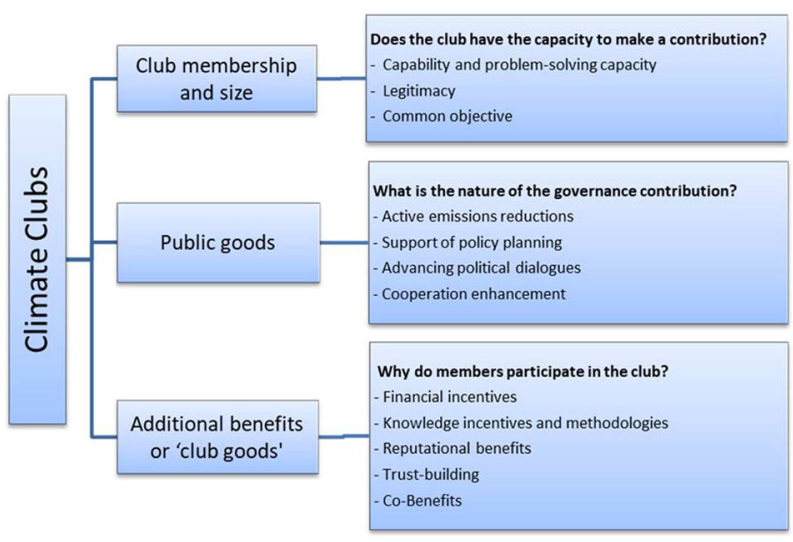

Fig. 1 The three clubs criteria. Illustration of the applied climate club criteria and their indicators (Source: the authors). countries (CCAC, 2017a), project implementation mainly takes place in developing countries.

The CCAC has a central objective: slowing the rate of nearterm global warming through the reduction of SLCPs (see CCAC, 2015a). SLCP is a political term aggregating several short-lived climate forcers (SLCFs) including black carbon, methane, hydrofluorocarbons (HFCs), and tropospheric ozone. Reducing SLCPs with currently available technologies could cut the current rate of warming in half and avoid $\sim 0.5^{\circ} \mathrm{C}$ of additional warming by 2050 (UNEP/WMO, 2011). Therefore, reductions in emissions of these non- $\mathrm{CO}_{2}$-forcers are essential to achieve the goal of the PA of keeping global warming well below $2{ }^{\circ} \mathrm{C}$. Further, they signify a contribution beyond the gases that have been covered by the UNFCCC, since black carbon and tropospheric ozone are not covered under this regime. The CCAC is currently the only globally active transnational initiative that deals with all four SLCPs. The CCAC does not set a collective emissions reduction targets or require its members to establish concrete objectives such as reduction pathways.

Among the other main objectives of the CCAC are promoting food security and energy efficiency while alleviating poverty. As SLCPs affect both global temperature and local and regional air quality, the CCAC stands at the intersection not only of different themes but also of governance levels. Consequently, SLCPs have a complex regulative and legal background. In national and international contexts they are regulated through several different institutions, including the UNFCCC and other environmental and air quality agreements such as the Convention on LongRange Transboundary Air Pollution (CLRTAP) and the Montreal Protocol (Yamineva and Romppanen, 2017). Being a voluntary international alliance, the CCAC has no legal personality, is nontreaty based and does not include binding commitments.

Looking back at the evolution of the CCAC since 2012, the CCAC started off as an initiative largely independent from the UNFCCC (Interview 2). In the beginning, it was even perceived to have a competitive relationship to the UNFCCC, and as a distraction from $\mathrm{CO}_{2}$ mitigation (Interviews 9, 11). Some members viewed the CCAC as an alternative to the paralyzed UNFCCC process, for instance at COP19 in Warsaw (Interview 10). Over the last several years, however, we have seen increasing convergence of the two agendas. The fact that the CCAC holds its High Level Assemblies (HLAs) and meetings often in parallel to the UNFCCC COPs is just one tangible sign of the cooperative intent of the CCAC with respect to the UNFCCC. But also the UNFCCC has recognized and invited the CCAC's expert knowledge on several occasions (Interview 2). For example, the CCAC was involved in the process of the Marrakesh climate action agenda, and was recognized as technical expert under the Ad Hoc Working Group on the Durban Platform for Enhanced Action (UNFCCC, 2014). CCAC's support of countries that wish to include SLCPs in their NDCs under the PA, as for example Mexico (Interview 7), can be seen as an example of "bottom-up" integration of SLCPs into the UNFCCC arena.

CCAC membership and size. The CCAC has managed to create what can be called a 'critical mass' that reunites members that have the capability and problem solving-capacity for action on near-term climate change: with large-emitter members such as Canada, the EU, India, and the USA, CCAC partners cover around $44 \%$ of the world's GHG in total ${ }^{3}$. The CCAC also includes many regions with high SLCP and air pollutant emissions; for example, 18 out of the 20 most polluted cities and 6 of the 10 world's largest cities are in CCAC countries ${ }^{4}$. Members can also be assumed to reunite economic capability to mitigate nearterm climate change, as together they represent $\sim 70 \%$ of the 
world's GDP ${ }^{5}$. Overall, members see the membership constellation as suitable, even though some would like to see potential candidates such as China, Brazil and Indonesia as part of the coalition, because they could achieve a very large impact in terms of SLCP reductions (Interviews 9, 10). The partnership has attracted new partners every year since its establishment.

The CCAC membership can also be considered to possess a high degree of legitimacy, uniting developed countries with high historical responsibility for climate change (e.g., the USA, and EU) with developing country members from Africa, Asia, and the Americas, who often struggle with air pollution problems. 44 of the 69 state partners are classified as low-income countries under the UNFCCC (2018). The transnational character of the CCAC can be seen as a great advantage in terms of capacities and knowledge (Interviews 3, 4, 9, 10). Non-state partners such as implementing agencies, research institutes, IGOs and subnational entities add to the CCAC's problem-solving capacity and increase its legitimacy. Notwithstanding the fact that non-state partners have no voting capacity in the CCAC steering committee, their role is often seen as an add-on by partners and in contrast to the UNFCCC process, non-state actors can actively participate on almost equal footing (Interviews 3, 4, 8, 9, 10). Many partners expressed this format was a motivation for joining (Interviews 4 , $7,8,9,10,11,13,6,9)$.

CCAC share a common objective of making progress on SLCP mitigation. Membership candidates have to endorse the Coalition Framework and propose meaningful action on SLCPs, identifying particular areas of interest. The coalition then has to approve the candidate (CCAC, 2014b). Even though there is no entrance fee or obligatory quantifiable commitments for candidates, members are expected to make monetary or non-monetary contributions. However, interviewees have claimed that many partners are not active at all or are unwilling to commit to significant action on SLCPs and that activity of members decreased over time, and that this is perceived as challenge, (Interviews 6, 7, 11, 10, 14). These observations are supported when examining the participation within the CCAC's thematic initiatives. ${ }^{6}$ The CCAC's inclusive format leaves much freedom for varying degrees of the quality and quantity of contributions. This apparently leads to a situation where some members are very active, while others' contributions can be close to zero. In principle, lacking activism can hint at free riding, that is, members enjoying the initiative's benefits without bearing any cost or making any contributions. Yet drastic measures, such as excluding or penalizing inactive members, do not seem to be on the coalition's agenda, even though the difference in activism is perceived as disadvantageous by some members.

We have found a discord with respect to the CCAC's size, which, with 145 members, is very large. While the large and diverse number of participants enriches the problem-solving capacity, such a large partnership almost resembles the numbers of parties under the UNFCCC. The large club size has the effect that within the coalition, many different interests, objectives and priorities exist. Interests of specific coalition partners range from the gaining scientific and methodological support from the CCAC (Interviews 7, 8, 10, 11, 13, 14), to the desire for funding of local mitigation and capacity-building activities (Interviews 10, 13, 14), to sector-specific or topic-specific initiatives within the CCAC, for instance, health (Interview 12) diesel (Interviews 13, 14), black carbon (Interview 7) and methane (Interview 9). Others want the CCAC to focus on SLCP emission reduction activities 'on-theground' and at scale (Interviews 6, 7, 8, 13, 14), or the support of partners' commitments under the PA and the implementation of their NDCs (Interviews 7, 13, 14). Still others see a strategic role within the international climate and air quality policy arenas as a provider of a broader political message as a priority: for example emphasizing the urgency of near-term emissions reductions (Interviews 10,11), and as a champion for the integration of climate and air quality agendas and policies (Interview 7). While many of these interests complement each other, some are rather contradictory. While such a flexible body as the CCAC is quite dynamic, it can also be difficult to manage the diverse interests, and partners see some drawbacks to the flexible membership structure (Interview 10).

CCAC's public goods. The CCAC actively engages in achieving emissions reductions to some degree. Within its 11 thematic initiatives, country and non-state partners jointly implement concrete projects that lead to SLCP reductions and often engage in capacity building and training measures for the local population. A concrete example is the brick initiative, which installed more efficient brick kilns in Nepal after its most recent major earth quake, reducing SLCP emissions as a result (CCAC, 2016a). Many additional CCAC activities have led to emission reductions. For example, the CCAC reports a reduction of 12,668 tons of methane emissions from the oil and gas sector in 2016-2017 (CCAC, 2017a).

In many cases, however, the data is insufficient to make a robust, quantitative accounting of emissions reductions based on coalition activities. One reason for this is specific to the focus of the CCAC: it targets a subset of pollutants (SLCPs) and sectors where the underlying technical data required for quantifying emission reductions is inadequate ${ }^{7}$ - even in the case of implemented mitigation projects. A second challenge to quantifying emissions reductions is the question of attribution: aside from mitigation projects that the coalition directly funded, it is difficult to attribute emissions reductions to the CCAC per se, even when it played a role, i.e., by working with country partner on a new policy. It is likewise difficult to attribute emissions reductions to activities like capacity building.

This aspect of the CCAC's governance activities is perceived as challenging. There is a general perspective with many interviewees that the effective implementation of emissions reductions are moving too slowly and that a scaling-up of activities or largescale mitigation activities would be necessary for progress (Interviews 6, 7, 8 10, 11, 14). This confirms our observation that only few numeric reduction goals and commitments can be found among members or the coalition in general. While the CCAC has a strategy, its 5-year plan, that includes a vision on how SLCP emission reductions can be achieved, it does not contain concrete emission reduction targets. Because of the CCAC's voluntary character, members do not have to make any quantifiable commitments on emission reductions. For example, the HLA communiqués, while gaining the attention of ministers and the top political level, remain somewhat inconcrete at the level of targets (see for example, CCAC, 2015b, 2016b, 2017b). At this point, rather than producing emission reductions at large scale, activities seem to have a flagship or "lighthouse" effect, providing an example to other regions and bringing SLCPs on the political agenda.

At the national and local level, the CCAC has incentivized and supported the development SLCP policies. The provision of planning support, methodologies, and capacity building has led to domestic regulation and programs in several cases (Interview $10,7)$. The CCAC reports that it has had a role in the development and adoption of 11 national laws, regulations or standards in the areas of diesel, waste and bricks policies in Australia, Colombia, Georgia, Ghana, Indonesia, Kenya, Mozambique and Nigeria (CCAC, 2017a). Further, the CCAC is actively supporting the implementation of international agreements, such as the PA and the Montreal Protocol with the Kigali Amendment. 
One way it has done this is by helping countries design national policies that fit into the international agreements: for example, Mexico has included a separate goal for the reduction of black carbon into its NDC, actively supported by the CCAC (Interview 7). CCAC also promotes the role of SLCP reductions as part of these agreements generally via its publications, events and research (for example CCAC, 2018).

The CCAC has also brought SLCPs to the attention of actors in the political arena, through advancing political dialogues. SLCPs have seen increased attention on the international stage, fostered by CCAC activities, such as Ministerial Roundtables and the regularly held HLAs. At such HLAs, ministers and heads of organizations generally endorse a joint political communiqué on SLCPs in line with CCAC priorities, e.g., the Bonn Communiqué of 2017 addressed SLCPs from agriculture and municipal solid waste (CCAC, 2017b). The topic of SLCPs was also recently taken up by the G7, at a ministerial roundtable on the sidelines of the UN General Assembly and by the General Assembly of the Parliamentary Confederation of the Americas. On both the national and international level, a main success of the CCAC is that of building knowledge and awareness on the topic of SLCPs. A majority of partners sees a main strength in the CCAC's work as establishing SLCPs as a topic per se, at governance levels ranging from the local to the international (Interviews 3, 4, 7, 10, $11,13,14)$. Bringing SLCPs on the political agenda and giving a neglected climate topic a voice internationally and in many national contexts can be counted as part of a governance activity.

Finally, cooperation enhancement certainly stands as one of the main governance successes of the CCAC. Partners see the creation of a large well-informed network and forms of close cooperation through regular exchange and coordinated work in the thematic initiatives that it offers as major asset of the CCAC (Interviews 4, 7, 8, 10, 11, 13). Regular discussions and exchange on scientific and technical topics paired with a very strong scientific basis provided by the Scientific Advisory Panel and inputs from non-state partners create a very sound basis for this initiative. The CCAC can therefore function as a 'playing field' where members try out activities and measures and debate topics in a more informal manner. The close working relationships within the CCAC can provide a different ground for further, potentially more formal negotiations in other contexts.

CCAC's additional benefits or 'club goods'. We find that the CCAC produces a number of additional benefits that incentivize candidates to become and stay members. The constant joining of new partners underscores this assumption.

Some CCAC members, primarily developing countries, receive financial incentives. They benefit from the funding of emission reductions projects, capacity-building measures and other financed support. On top of this, the CCAC facilitates the generation of funding from other sources, such as the Green Climate Fund (GCF) or the private sector. However, this is not strictly an excludable good since some supported activities take place in non-members countries. Hence, funding is not entirely exclusive to members. Through the application of CCAC methodologies, non-members may also have indirect economic benefits. Notwithstanding, partners describe not only the methodologies and funding per se, but also the support provided by the CCAC in realizing them as a benefit (Interviews 7, 13, 14).

The CCAC produces capacities through knowledge incentives and methodologies: knowledge, expertise and experience through its network, but also knowledge products, tools and technologies. For example, the Long-range Energy Alternatives PlanningIntegrated Benefits Calculator (LEAP-IBC) is a planning tool that helps governments to assess GHG, SLCPs and other air pollutant emissions (Stockholm Environment Institute, 2018). These products are produced primarily for and used by the partners (e.g. Interviews 13,14$)$. However, not all are entirely exclusive, as some are available on the CCAC homepage.

Partners described how the CCAC's work has reputational benefits with a legitimizing effect. The CCAC seems to have established a label that helps to validate the quality of certain methodologies or projects. This has also helped politics: it provides policy makers with an argumentation for the use of integrative environmental approaches and innovative methodologies (Interviews 6, 11).

Finally, also trust-building has been relevant in this case. There is strong added value to the regular technical exchange and cooperation. The CCAC meets at least twice per year and sometimes also at further events; partners also work closely together in the initiatives. They describe the collaboration as positive and fruitful and as having a very special and unique atmosphere. It allows for a different, more productive and positive dialogue than in other, country-exclusive forums (Interviews 3, 4, 8, 9, 10, 11). Work within the CCAC is different than larger fora, e.g. the UNFCCC, and this is part of its success (Interview 10). Members therefore have an advantage because they know each other better and may have a better sense of which policy is acceptable and what not for other regions.

Through working at the intersection of air quality and climate change, the CCAC also provides near-term co-benefits for sustainable development: In addition to the global near-term warming mitigation, SLCP mitigation improves public health and avoids premature deaths by improving air quality. It also prevents millions of tons of crop losses yearly. As these effects occur first of all locally ${ }^{8}$, the largest benefit goes to the implementing CCAC member.

\section{Conclusion}

Although the CCAC can draw on success stories related to emissions reductions, these projects have been modest in terms of tonnes of emissions reduced, and represent flagship and "best practice" examples rather than large-scale implementation. Overall, we find that the CCAC's largest value lies in those activities that contribute more indirectly towards emissions reductions, preparing and catalyzing their (future) realization. Within the CCAC, this is a point of discussion: some members would like to see the focus of the CCAC shift more strongly towards large-scale implementation of mitigation activities. However, it is difficult to imagine such a change, as long as there is no significant expansion of the funding and the club does not require any reduction commitments from its members.

We find that the CCAC can still make a valuable contribution to international climate governance: it has acted as a pace maker for a neglected topic and prepared the field for the implementation of SLCP reductions. The CCAC has been very successful in raising awareness among policy makers from different governance levels regarding the importance of SLCP reductions for climate, air quality, and sustainable development. Furthermore, it has incentivized local and national SLCP policy making, supporting the development of national laws, regulations, and standards, which promise to reduce emissions in the future. As the single international alliance on SLCPs, it further has a role in the orchestration of actors and actions on near-term warming and in the establishment of a large and well-functioning network for cooperation based on regular exchange, a close working relationship and sound scientific knowledge. It coordinates efforts from the very local to the global governmental level, and manages 
actors from science, NGOs, and governmental representatives, integrating them horizontally.

Within the broader climate governance landscape, the CCAC is an innovative actor that seeks to achieve its objectives through voluntary cooperation. The CCAC has evolved over time: it started off as a group of only a few actors but now has turned into a fora-style coalition with a large and relevant membership. We have found that the different actors have diverse and sometimes conflicting interests, which we infer could make it challenging to agree on common objectives and actions. The diversity of interests could be one explanation for why few commitments and concrete reduction goals can be found within the CCAC. In this regard, the CCAC also resembles large fora such as the UNFCCC. A trade-off exists between the club's problem-solving capacity and relevance, which increases with large membership, and its decision-making ability, which is challenged the more members and interests are involved. Yet the CCAC, in contrast to the UNFCCC, seeks to cope with this situation by giving its steering committee an outstanding authority over central decisions.

We see the CCAC as complementary to the UNFCCC process, in a role which has also evolved over time. While at its origins the CCAC was perceived as having a competitive character to the UNFCCC process, the CCAC has established SLCP mitigation as clearly complementary to $\mathrm{CO}_{2}$ reductions, with widespread support for its actions. It occupies a unique niche in tackling SLCPs at the intersection of climate and air quality policy. Moreover, our analysis suggests that CCAC's activities promise progress that likely would not have been achieved under the UNFCCC. Not only because it focuses on pollutants beyond the Kyoto gases, but also because the CCAC prepares and to some degree implements additional emissions reduction measures tackling SLCPs, and is in this regard involved in achieving the PA's mitigation targets. CCAC has the ambition and potential to further contribute to bridging the gap between committed and necessary emissions reductions by proposing concrete pathways to implement the PA. As SLCPs have no work stream under the PA and only very few countries include specific SLCP measures in their NDCs, the CCAC can lay the groundwork for action that goes beyond what countries have so far promised in their NDCs. With an estimated potential of avoiding $0.5^{\circ} \mathrm{C}$ (UNEP/WMO, 2011) of global warming, SLCP mitigation can make a very significant contribution to meeting the PA's targets.

Furthermore, the CCAC has the potential to contribute to an integrating governance function in several regards: it tackles the overlaps of different legal regimes, such as the UNFCCC, the Montreal Protocol, the CLRTAP, and the Sustainable Development Goals (SDGs); it integrates different policy fields namely climate, air quality and sustainable development policy; and it brings together diverse expertise from politics, science and civil society. Such a function could be valuable within the observed fragmented climate policy regime.

In addition to its climate governance functions as expanded upon above, we find the CCAC's outstanding value to its members lies in providing 'additional' benefits beyond climate change mitigation via its emphasis on local, near-term benefits that come with improving air quality. Although co-benefits for air quality and sustainable development cannot be entirely excluded from non-members, these gains, in addition to knowledge, methodologies, reputational benefits and trust-building, benefit members first and foremost and provide reason for joining and staying in the CCAC, as also evidenced by its growing membership. Nonetheless, the observed lack of activity among some members might also point to their dissatisfaction with the activities carried out or the benefits provided. This could generate another tradeoff for the coalition, between gaining interest from new members vs. maintaining engagement of the existing members.
From a conceptual perspective, we see that the role of the CCAC comes closer to some concepts that perceive clubs as transnational actors within a building blocks strategy: CCAC moves the incentive structure beyond climate change mitigation, and can prepare the implementation of policies and agreements via efforts additional to the UNFCCC. Generally, the clubs conceptualization provided an insightful basis for our analytical framework, supporting the understanding of how an innovative governance actor functions, and for examining the contributions it makes within the international climate arena. The clubs framework was useful despite the finding that some of the CCAC's characteristics go beyond what has often been considered a climate club. The CCAC can be seen as a product of its time, consistent with the formats of today's climate clubs generally: where participation is relatively easy and no or few obligations exist (Weischer et al., 2012), and which can alternately be seen as voluntary environmental clubs or even pseudo-clubs (Green, 2015).

\section{Outlook}

Overall, we expect the CCAC to deepen its work on implementing existing international agreements such as the Montreal Protocol and the PA. One pathway already underway in this regard is that of encouraging further countries to integrate SLCPs into their national climate planning, including NDCs. Nevertheless, the described situation of diverging interests and objectives raises the question on where this partnership is going. Towards stronger technical specialization, large-scale reduction project implementation or stronger single country commitments? The limited funding suggests that the strengthening of its political work, such as the fostering of political dialogue, will still be the most significant future function of the CCAC, rather than largescale project implementation. Our glimpse into the practice suggests that climate initiatives vary over time in their format and constellation. Interviewees referring to a group of especially active partners raise speculations that in the future we could find here a 'coalition of the willing among the willing' or a 'club within the club'. These partners could drive forward ambitious action on SLCPs in a smaller group or in a special initiative within or outside the CCAC. Finally, our paper points to further questions to be assessed in future research. For example, it would be important to examine how the growing membership and associated interests and workload affect the coalition's ability to provide 'club' benefits such as trust, reputation, and sharing of the limited funding, and to examine how benefits and costs are shared between state and non-state members. A comparative analysis of the CCAC in relation to other transnational and club actors in the global climate governance landscape could provide further insights.

\section{Data availability}

\section{Interviews}

Interview 1: 04.05.2018 (preliminary talk)

Interview 2: 26.04.2018

Interview 3: 21.08.2018

Interview 4: 29.08.2018

Interview 5: 03.09.2018

Interview 6: 02.10.2018

Interview 7: 19.09.2018

Interview 8: 04.10.2018

Interview 9: 05.10.2018

Interview 10: 09.10.2018

Interview 11: 09.10.2018

Interview 12: 12.10.2018

Interview 13: 17.10.2018 
Interview 14: 21.09.2018

Interviews were carried out with experts from CCAC country members from Africa, the Americas, Asia, and Europe; the CCAC Secretariat; intergovernmental organizations based in Europe and the Americas; scientific institutes based in Asia and Europe and a NGO based in Europe. The datasets generated during the current study through expert interviews, such as interview transcripts and notes, are not publicly available in order to keep individuals' privacy, but are available from the corresponding author on reasonable request.

Received: 7 November 2019; Accepted: 22 April 2020; Published online: 19 May 2020

\section{Notes}

1 The authors have taken part in CCAC activities including working group meetings, teleconferences and writing of reports.

2 In practice, policy development often takes place at national and subnational levels, and policy support could have an exclusive character if only club members benefit from it.

3 Analysis by the authors based on data published by UNFCCC (n.d.), UNEP (2018) and The World Bank (2019).

4 Analysis by the authors based on published by UN (2018) and Sauter (2019) on the World Health Organization (WHO) Global Ambient Air Quality Database.

5 For our analysis, these numbers can only serve as proxy for membership relevance, but no in-depth investigation on their effect on the CCAC was undertaken.

6 The CCAC website displays which partners are active in the different thematic initiatives.

7 For the pollutant black carbon, for example, there are still large uncertainties in global emissions inventories, and emission factors and activity data are largely lacking for sectors where the CCAC is active, e.g., the traditional bricks sector in large parts of South America, Asia, and Africa. The situation is similar in the household cooking and heating sector in developing countries, where the CCAC is also active.

8 The impact of air pollution (and the benefits of emission reductions) is greatest closest to the source of pollution (e.g., traffic, industry). Some pollutants, including methane for example, have a long enough atmospheric residence time that they also have an impact far from their emission sources.

\section{References}

Abbott KW (2012) The transnational regime complex for climate change. Environ Plan C 30(4):571-590. https://doi.org/10.1068/c11127

Abbott KW, Genschel P, Snidal D et al. (2015) International organizations as orchestrators. Cambridge University Press, Cambridge, New York

Barret S (2008) Climate treaties and the imperative of enforcement. Oxf Rev Econ Policy 24(2):239-258

Biermann F, Pattberg P, Van Asselt H et al. (2009) The fragmentation of global governance architectures: a framework for analysis. Glob Environ Politics 9 (4):14-40

Buchanan JM (1965) An economic theory of clubs. Economica 32(125):1-14

Bulkeley H, Andonova LB, Betsill MM et al. (2014) Transnational climate change governance. Cambridge University Press, New York

CCAC (2014a) Framework for the Climate and Clean Air Coalition to reduce short-lived climate pollutants. Climate and Clean Air Coalition. http://www. ccacoalition.org/ru/resources/climate-and-clean-air-coalition-ccacframework-document. Accessed 24 Oct 2018

CCAC (2014b) Guidelines \& rules of engagement for coalition partners, actors and implementers-compilation of decisions. http://www.ccacoalition.org/en/ resources/climate-and-clean-air-coalition-ccac-guidelines-rules-engagement. Accessed 1 Nov 2018

CCAC (2015a) 5-year strategic plan (2020). Climate and Clean Air Coalition. http://www.ccacoalition.org/fr/resources/climate-and-clean-air-coalitionfive-year-strategic-plan. Accessed 16 Oct 2018

CCAC (2015b) Paris communique. Climate and Clean Air Coalition. http:// ccacoalition.org/en/resources/paris-communique. Accessed 4 Apr 2019

CCAC (2016a) Bricks success story: Nepal building back better. http://www. ccacoalition.org/en/news/bricks-success-story-nepal-building-back-better. Accessed 1 Nov 2018

CCAC (2016b) Vienna communique. Climate and Clean Air Coalition. https:// www.ccacoalition.org/en/resources/vienna-communique. Accessed $4 \mathrm{Apr}$ 2019
CCAC (2017a) Annual report 2016-2017. Climate and Clean Air Coalition. http:// www.ccacoalition.org/en/resources/climate-clean-air-coalition-annualreport-2016-2017. Accessed 15 Oct 2018

CCAC (2017b) Bonn communique. Climate and Clean Air Coalition. http:// ccacoalition.org/en/resources/bonn-communique. Accessed 4 Apr 2019

CCAC (2018) Ministerial roundtable discussion. Climate and Clean Air Coalition. http://ccacoalition.org/en/resources/key-messages-ministerial-roundtablesession-new-york-26-sep-2018. Accessed 4 Apr 2019

Chan S, Ellinger P, Widerberg O (2018) Exploring national and regional orchestration of non-state action for a $<1.5^{\circ} \mathrm{C}$ world. Int Environ Agreem: Politics Law Econ 18(1):135-152. https://doi.org/10.1007/s10784-018-9384-2

Eckersley R (2012) Moving forward in the climate negotiations: multilateralism or minilateralism? Glob Environ Politics 12(2):24-42. https://doi.org/10.1162/ GLEP_a_00107

Falkner R (2016) A minilateral solution for global climate change? On bargaining efficiency, club benefits, and international legitimacy. Perspect Politics 14 (1):87-101. https://doi.org/10.1017/S1537592715003242

Falkner R, Stephan H, Vogler J (2010) International climate policy after Copenhagen: towards a 'building blocks' approach. Glob Policy 1(3):252-262. https://doi.org/10.1111/j.1758-5899.2010.00045.x

Graichen J, Healy S, Siemons A et al. (2016) International Climate Initiatives-a way forward to close the emission gap? Initiatives' potential and role under the Paris Agreement. 31/2016. Umweltbundesamt, Dessau-Roßlau. https://www. umweltbundesamt.de/sites/default/files/medien/1968/publikationen/2016-1129_discussion_paper_clean_version_final.pdf. Accessed 30 Apr 2019

Green JF (2015) The strength of weakness: pseudo-clubs in the climate regime. Clim Change 144(1):41-52. https://doi.org/10.1007/s10584-015-1481-4

Gupta A, Pistorius T, Vijge MJ (2016) Managing fragmentation in global envir onmental governance: the REDD+Partnership as bridge organization. Int Environ Agreem: Politics Law Econ 16(3):355-374. https://doi.org/10.1007/ s10784-015-9274-9

Hale T (2011) A climate coalition of the willing. Wash Q 34(1):89-101

Hannam PM, Vasconcelos VV, Levin SA et al. (2017) Incomplete cooperation and cobenefits: deepening climate cooperation with a proliferation of small agreements. Clim Change 144(1):65-79. https://doi.org/10.1007/s10584-015-1511-2

Hermwille L (2018) Making initiatives resonate: how can non-state initiatives advance national contributions under the UNFCCC? Int Environ Agreem: Politics Law Econ 18(3):447-466. https://doi.org/10.1007/s10784-018-9398-9

Hovi J, Sprinz DF, Sælen H et al. (2016) Climate change mitigation: a role for climate clubs? Palgrave Commun 2(1). https://doi.org/10.1057/palcomms.2016.20

Hovi J, Sprinz DF, Sælen H et al. (2017) The club approach: a gateway to effective climate co-operation? Br J Political Sci. Cambridge University Press. 49, 1071-1096

Jang J, McSparren J, Rashchupkina Y (2016) Global governance: present and future. Palgrave Commun 2:15045

Jordan AJ, Huitema D, Hildén M et al. (2015) Emergence of polycentric climate governance and its future prospects. Nat Clim Change 5(11):977-982. https:// doi.org/10.1038/nclimate2725

Keohane RO, Victor DG (2011) The regime complex for climate change. Perspect Politics 9(1):7-23

Keohane RO, Victor DG (2016) Cooperation and discord in global climate policy. Nat Clim Change 6(6):570-575

Iacobuta G, Dubash NK, Upadhyaya P et al. (2018) National climate change mitigation legislation, strategy and targets: a global update. Clim Policy 18 (9):1114-1132. https://doi.org/10.1080/14693062.2018.1489772

Michaelowa K, Michaelowa A (2017) Transnational climate governance initiatives: designed for effective climate change mitigation? Int Interact 43(1):129-155 https://doi.org/10.1080/03050629.2017.1256110

Naím M (2009) Minilateralism: the magic number to get real international action. Foreign Policy 173:136-135

Nordhaus W (2015) Climate clubs: overcoming free-riding in international climate policy. Am Econ Rev 105(4):1339-1370

Oberthür S (2016) Reflections on global climate politics post paris: power, interests and polycentricity. Int Spect 51(4):80-94. https://doi.org/10.1080/ 03932729.2016.1242256

Olson M (1971) Increasing the incentives for international cooperation. Int Organ 25(4):866-874

Ostrom E (2010) Polycentric systems for coping with collective action and global environmental change. Glob Environ Change 20(4):550-557

Pattberg P, Widerberg O (2017) The climate change regime. In: von Storch H (ed.) Oxford research encyclopedia of climate science. Oxford University Press

Pattberg P, Widerberg O, Isailovic M et al. (2014) Mapping and Measuring fragmentation in global governance architectures: a framework for analysis. R-14/ 34, Working Paper. IVM-Institute for Environmental Studies, Amsterdam

Potoski M (2017) Green clubs in building block climate change regimes. Clim Change 144(1):53-63. https://doi.org/10.1007/s10584-015-1517-9 
Prakash A, Potoski M (2006) The Voluntary Environmentalists: Green Clubs, ISO 14001, and Voluntary Environmental Regulations. Cambridge University Press, New York

Prakash A, Potoski M (2007) Collective action through voluntary environmental programs: a club theory perspective. Policy Stud J 35(4):773-792

Sabel CF, Victor DG (2015) Governing global problems under uncertainty: making bottom-up climate policy work. Clim Change 144(1):15-27. https://doi.org/ 10.1007/s10584-015-1507-y

Sælen H (2016) Side-payments: an effective instrument for building climate clubs? Int Environ Agreem: Politics Law Econ 16(6):909-932. https://doi.org/ 10.1007/s10784-015-9311-8

Sauter M (2019) 28 Most polluted cities in the world. https://247wallst.com/specialreport/2019/11/04/28-most-polluted-cities-in-the-world-2/8/ Analysis carried out for 24/7 Wall St. based on WHO Global Ambient Air Quality Database. https://whoairquality.shinyapps.io/AmbientAirQualityDatabase/. Accessed 20 Feb 2020

Stewart RB, Oppenheimer M, Rudyk B (2013) A new strategy for global climate protection. Clim Change 120(1):1-12. https://doi.org/10.1007/s10584-0130790-8

Stewart RB, Oppenheimer M, Rudyk B (2017) Building blocks: a strategy for nearterm action within the new global climate framework. Clim Change 144 (1):1-13. https://doi.org/10.1007/s10584-017-1932-1

Stockholm Environment Institute (2018) The long-range energy alternatives planning-Integrated Benefits Calculator (LEAP-IBC). http://www. ccacoalition.org/en/resources/long-range-energy-alternatives-planningintegrated-benefits-calculator-leap-ibc-factsheet. Accessed 1 Nov 2018

The World Bank (2019) GDP (current US\$). https://data.worldbank.org/indicator/ NY.GDP.MKTP.CD? end=2018\&start $=1960 \& v i e w=$ chart. Accessed $20 \mathrm{Feb}$ 2020

UN (2018) The world's cities in 2018-Data Booklet. Department of Economic and Social Affairs, Population Division (ST/ESA/ SER.A/417). https://www.un. org/en/events/citiesday/assets/pdf/the_worlds_cities_in_2018_data_booklet. pdf. Accessed 20 Feb 2020

UNEP (2018) Emissions gap report 2018. United Nation Environment Programme. http://wedocs.unep.org/bitstream/handle/20.500.11822/26895/EGR2018 FullReport_EN.pdf?sequence=1\&isAllowed=y. Accessed 4 Apr 2019

UNEP/WMO (2011) Integrated assessment of black carbon and tropospheric ozone: summary for decision makers. Twenty-sixth Session of the Governing Council/Global Ministerial Environment Forum, Nairobi, Kenya. https:// www.ccacoalition.org/en/resources/integrated-assessment-black-carbon-andtropospheric-ozone. Accessed $20 \mathrm{Feb} 2020$

UNFCCC (n.d.) Greenhouse Gas Inventory Data-detailed Data by Party. https:// di.unfccc.int/detailed_data_by_party. Accessed 20 Feb 2020

UNFCCC (2014) Expert meeting: ADP technical expert meetings: non-CO2 greenhouse gases. https://unfccc.int/process-and-meetings/conferences/ past-conferences/bonn-climate-change-conference-october-2014/eventsand-programme/mandated-events/adp-technical-expert-meetings-nonco2-greenhouse-gases. Accessed 1 Nov 2018

UNFCCC (2018) List of parties. https://unfccc.int/process/parties-non-partystakeholders/parties-convention-and-observer-states?field_national_ communications_target_id\%5B514\%5D $=514$. Accessed 20 Feb 2020

Victor DG (2015) The case for climate clubs. E15 Initiative. ICTSD International Centre for Trade and Sustainable Development/World Economic Form. http://www.e15initiative.org/. Accessed 4 Apr 2019

Victor DG (2017) Three-dimensional climate clubs: implications for climate cooperation and the G20. Climate and Energy: Think Piece. ICTSD Inter- national Centre for Trade and Sustainable Development. https://www.ictsd. org/sites/default/files/research/three-dimensional_climate_clubs_and_ the_g20-david_victor.pdf. Accessed 4 Apr 2019

Victor DG, Carraro C, Olmstead SM (2007) Fragmented carbon markets and reluctant nations: implications for the design of effective architectures. In: Aldy JE, Stavins RN (eds) Architectures for agreement: addressing global climate change in the post-Kyoto world. Cambridge University Press, Cambridge, pp. 133-184

Weischer L, Morgan J, Patel M (2012) Climate clubs: can small groups of countries make a big difference in addressing climate change? Rev Eur Community Int Environ Law 21(3):177-192

Widerberg O, Stenson DE (2013) Climate clubs and the UNFCCC. Fores Study 3:1-52. https://fores.se/wp-content/uploads/2013/11/ClimateClubsAndTheUNFCCCFORES-Study-2013-3.pdf. Accessed 2 Feb 2019

Yamineva Y, Romppanen S (2017) Is law failing to address air pollution? Reflections on international and EU developments. Rev Eur Comp Int Environ Law 26(3):189-200. https://doi.org/10.1111/reel.12223

Zelli F (2011) The fragmentation of the global climate governance architecture: fragmentation of the global climate governance architecture. Wiley Interdiscip Rev: Clim Change 2(2):255-270. https://doi.org/10.1002/wcc.104

\section{Acknowledgements}

We would like to acknowledge the support from Christine Bindal as well as fruitful discussions with CCAC members and the Secretariat, as well as IASS colleagues.

\section{Competing interests}

The authors declare no competing interests.

\section{Additional information}

Correspondence and requests for materials should be addressed to C.U.

Reprints and permission information is available at http://www.nature.com/reprints

Publisher's note Springer Nature remains neutral with regard to jurisdictional claims in published maps and institutional affiliations.

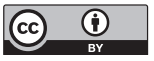

Open Access This article is licensed under a Creative Commons Attribution 4.0 International License, which permits use, sharing, adaptation, distribution and reproduction in any medium or format, as long as you give appropriate credit to the original author(s) and the source, provide a link to the Creative Commons license, and indicate if changes were made. The images or other third party material in this article are included in the article's Creative Commons license, unless indicated otherwise in a credit line to the material. If material is not included in the article's Creative Commons license and your intended use is not permitted by statutory regulation or exceeds the permitted use, you will need to obtain permission directly from the copyright holder. To view a copy of this license, visit http://creativecommons.org/ licenses/by/4.0/.

(C) The Author(s) 2020 